\title{
Puerto Rican Neodexiopsis (Diptera: Muscidae: Coenosiinae)
}

\author{
Fred M. Snyder \\ INTRODUCTION
}

The following species are described in order to have names to place on a valuable collection of Neodexiopsis Malloch made by J. Maldonado Capriles and associates.

The following commonly accepted abbreviations are used:

$\mathrm{T} 1, \mathrm{~T} 2, \mathrm{~T} 3=$ fore, $\mathrm{mid}$ and hind tibiae.

$\mathrm{F} 1, \mathrm{~F} 2, \mathrm{~F} 3$ = fore, mid and hind femora.

$a=$ anterior

$v=$ ventral

$a d=$ anterodorsal

$a v=$ anteroventral

$d=$ dorsal

$i a=$ intraalar bristles

$p d=$ posterodorsal

$s t=$ sternopleural bristles

$p=$ posterior

$a c=$ acrostical bristles or setulae

$p v=$ posteroventral

$d c=$ dorsocentral bristles

In describing the width of the front at vertex, the measurement is made at the level of the strong, upright pair of posterior parafrontal bristles and is compared with a measurement made at the widest part of the head. Width of the third antennal segment is the maximum anterior-to-posterior distance at right angles to the dorsoventral axis of the antennae when they hang ventrally. Length of the antennae is measured on the outer (lateral) surface when the head is viewed in profile. The head is described as viewed frontodorsally, except as noted, and the thorax and abdomen as viewed posterodorsally. There are several long bristles on the $a, a d$ and $p d$ surfaces of T3 which are important specific, generic, or subgeneric characters; there is a tendency for certain of these to vary slightly in position. All can be rationalized if the tibiae are assumed to be octagonal in cross section $(1,3)^{2}$. In Nearctic species, the dorsal bristle, $(d)$ is relatively short, and situated preapically; but in Neotropical species, it is frequently quite long and sometimes situated so close to the middle of T3 that it might be confused with either an $a d$ or $p d$ bristle. The use of the term, "mid $d$ ", is to qualify the position of this bristle as being on the midline of the $d$ surface, and not midway from base to apex of T3.

Holotypes of the new species are deposited in the U.S. National Museum collection, though certain duplicate paratypes are retained in the author's collection.

18405 Loch Raven Boulevard, Towson 4, Md., U. S.

2 Italic numbers in parentheses refer to Literature Cited, p. 229. 
Grateful acknowledgment is made to C. W. Sabrosky of the U. S. Department of Agriculture for making this material available for study in connection with a proposed treatment of the New World species of Neodexiopsis. To F. van Emden of the Commonwealth Institute of Entomology, I am grateful for tracing specimens of flavipes Williston through the key, and to C. H. Curran of the American Museum of Natural History, I am also grateful for the loan of the type of his rex for study and comparison.

\section{GENUS: NEODEXIOPSIS MALLOCH}

Dexiopsis Stein, 1897, (nec Pokorny), Berliner Ent. Zeitschr., 42: 259.

Neodexiopsis Malloch, 1920, Trans. Amer Ent. Soc., 46: 162.

Coenosia (Neodexiopsis) Huckett, 1934, op. cit., 60: 73.

Coenosia Malloch, 1934, Dipt. Patagonia and South Chile, 7 : (2) p. 210, (in part).

Austrocoenosia Malloch, 1934, op. cit., p. 217 (in part).

This group, as redefined by Huckett (1934, p. 74), differs from other Coenosia Meigen, sensu lato, in having three preapical bristles on F3: an $a d, d$ and $p d$ to $p$ bristle. The position of the third bristle is quite variable, but is always situated on either the $p d$ or $p$ surfaces and in combination with two other apical bristles, which are situated somewhere between the $a d$ and $d$ surfaces, will distinguish this group from its closest relatives, e.g., Limosia Robineau-Desvoidy, and Coenosia Meigen, sensu stricto (= Caricea Robineau-Desvoidy of authors).

Males of micans and crassicrurus, described below, lack this usual arrangement of $\mathrm{F} 3$ bristles due to the considerable modification of shape and accessory bristling of $\mathrm{F} 3$, but since associated females possess the typical three preapical bristles on F3, the two species noted above are included in Neodexiopsis.

Other peculiarities of several of the species in the collection are the atypical arrangment of sternopleural bristles which are not in the form of an equilateral triangle, the presence of a single postsutural intraalar bristle on each side, and the absence of duplicated propleural and stigmatal bristles. These characters, coupled with the extreme modification of certain leg bristles, femoral and tibial shape in some of the species, doubtless represent extreme evolutionary trends in isolated insular populations. More extensive collections from other Caribbean Islands will be necessary before relationships of these aberrant Puerto Rican species with North and South American species can be rationalized.

\section{KEY TO PUERTO RICAN NEODEXIOPSIS}

1. Apical scutellar bristles usually much less than 0.66 as long as subbasals. . . . . . . . . . . . . . . . . . . . . . . . . 9 
Apical scutellar bristles at least 0.75 as long as subbasals.......2

2. Postsutural ia 1........................... rex Curran

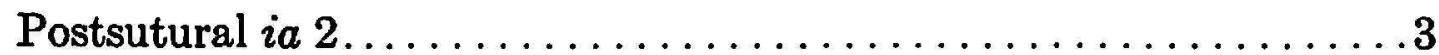

3. Males. . . . . . . . . . . . . . . . . . . . . . . . . . .

Females. . . . . . . . . . . . . . . . . . . . . . . .

4. T3 with several rows of numerous, long, bristly hairs on $d, p d$ and $a$ surfaces, many of which are almost as long as length of T3; third antennal segment fulvous. . . . . . . . . . . . . . . . . . . . 6

T3 with not more than 5 bristles, including apicals, and without accessory long, bristly hairs; third antennal segment dark........5

5. Femora mostly or entirely fulvous; T3 without a submedian av bristle; abdomen with at least the basal portion of first visible tergite yellow to fulvous................... discolorisexus, new species

Femora mostly or entirely fuscous; T3 with a submedian av bristle or setula; abdomen entirely fuscous in ground color

ditiportus, new species

6. Posterior margin of wing with a shallow longitudinal incision on basal $0.5 \ldots \ldots \ldots \ldots \ldots \ldots \ldots \ldots \ldots \ldots \ldots \ldots \ldots \ldots \ldots \ldots \ldots \ldots$ cavala, new species Posterior margin of wing not incised.........medinai, new species

7. Femora mostly dark ......................

Femora mostly yellow to fulvous....................

8. T3 with a median $a v$ bristle or setula; anterior ocellar bristles subequal to anterior parafrontals; trochanters dark

ditiportus, new species

T3 without a median av bristle; anterior ocellar bristles less than 0.5 as long as anterior parafrontals; trochanters yellow to fulvous discolorisexus, new species

9. Postsutural ia 2.................................10

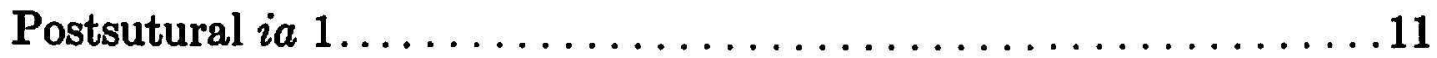

10. Antennae mostly or entirely fuscous.......maldonadoi, new species Antennae mostly or entirely fulvous......... neoflavipes, new species

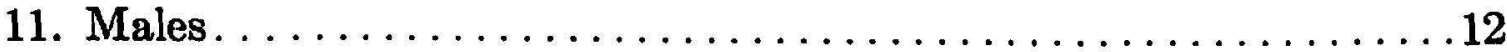

Females....................................

12. T2 with a single long $a$ and $p$ bristle slightly beyond middle; most of the apical bristles extremely long and hairlike; T3 without numerous, long, accessory hairs or bristles; with 2 stigmatal bristles

crispiseta, new species

T2 with several long $a$ and $p$ bristles or hairs on apical 0.5 ; T3 with numerous long, accessory hairs or bristles; with a single stigmatal bristle. 
13. T2 distinctly thickened on apical 0.4 , with numerous, long, curly ad and $p d$ bristles on this enlarged portion; in frontal view, the frons with dense silvery white pruinescence, the triangle not differentiated; abdomen with the usual dorsal pruinescence and clothing setulae

crassicrurus, new species

T2 not unusually thickened on apical 0.4 , with $1 a$ to $a d$ bristle, and several $p d$ on median 0.5 ; in frontal view, frons with dense brownish pruinescence, the triangle differentiated; abdomen shiny dorsally, without or with only sparse clothing setulae.... micans, new species

14. Palpi, fore coxae and basal 0.8 or more of F2 and F3 fuscous

ebenifemur, new species

Palpi, fore coxae and basal 0.8 or more of at least $\mathrm{F} 2$ and $\mathrm{F} 3$ yellow

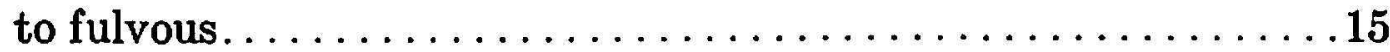

15. Stigmatal and propleural bristles duplicated; F2 with 2 apical $p$ to $p d$ bristles......................... crispiseta, new species Stigmatal and propleural bristles not duplicated; F2 with a single apical $p$ to $p d$ bristle. ............................ 16

16. T2 with 2 submedian $p$ bristles...........crassicrurus, new species T2 with 1 submedian $p$ bristle............micans, new species

\section{NEODEXIOPSIS REX CURRAN}

Curran, 1928, Scientific Survey Puerto Rico and Virgin Islands, 11:88.

Male, $3.7 \mathrm{~mm}$. long. Head black, with dense silvery gray pruinescence; the frontal vitta brownish gray pruinescent; the frontal triangle narrowly complete. Front at vertex 0.27 of head width, gradually widened to 0.30 at base of antennae. In profile, juncture of parafacials and parafrontals $0.5-0.8$ as long as the greatest width of third antennal segment, parafacials obscured below. Cheeks 0.5 as high as width of third antennal segment. Anterior ocellars about 0.5 as long as postocellars, and the latter subequal to the anterior parafrontals. Inner verticals subequal to postocellars; outer verticals about 2 times as long as the setulae in postoccular row. The setulose hairs on lower margin of cheeks and posterior portion of head yellow. Antennae dark; yellowish on basal $0.50-0.33$ of third and at apex of second segments, all densely gray pruinescent; antennae inserted opposite dorsal 0.4 of eyes and extending almost to opposite their lower margin; third segment 3.0 times as long as second. Arista dark, subshiny, the longest hairs very slightly longer than greatest aristal diameter. Palpi light brown to dark yellow.

Thorax black; densely bluish gray to grayish pruinescent; presuturally with a trace of 3 brown vittae which become expansive, subconfluent and blend into a darkened area along $i a$ plane postsuturally. Setulae on humeri and anterior declivities of mesonotum normal; $a c$ setulae irregularly bi- 
seriate; prescutellars scarcely differentiated; ia 1 ; the stigmatal and propleural bristles with a very slender, duplicating bristle. Apical scutellars as long as subbasals; st in an equilateral triangle.

Legs yellow, the tarsi and a limited dorsal apical area of F2 and F3 brownish. F1 normal, the few short av setulae at base not spinulose. T1 with a median $p$ bristle; the mid $d$ slightly longer than the $p d$, the former inserted only slightly based to the latter and both longer than T1 diameter; the apical $p v$ about 0.5 the length of $p d . F 2$ with a series of slender, apically curved, av bristles, those on basal 0.25 longer than $\mathrm{F}$ diameter and the others about as long as $\mathrm{F}$ diameter where situated; with 5-6 stronger $v$ bristles, the basal 3-4 longest; and with 1-2 slender submedian $a$, and 2 preapical $p$ bristles. T2 with a median $a$ and $p$ bristle; the apical ad not differentiated and the apical $p d$ only slightly longer than T2 diameter. F3 with a row of slender apically curved $a v$ and $p v$ bristles, several of which are longer than $\mathrm{F}$ diameter and others subequal to diameter where situated, but without a distinct apical av bristle opposite the terminal one in $a d$ row. T3 with a median $a d$ and $p d$ bristle, the mid $d$ situated on apical $0.20-0.25$, the preapical $a d$ about 0.5 as long as mid $d$ and 2 times as long as T diameter.

Wings hyaline, with a very faint brownish tinge. Costal thorns and setulae short. Calyptrae white. Halteres yellowish white.

Abdomen elongate, somewhat broadened at middle and dorsoventrally thickened apically; fulvous yellow, with a dense, grayish pruinescent, triangular area at basolateral corner of all tergites; these areas largely devoid of clothing setulae; the dorsum of first 2 tergites subshiny yellow; the third and fourth mostly darkened dorsally, subshiny; with very short, dense decumbent clothing setulae on all tergites. Basal hypopygial segment grayish pruinescent, moderately distinct in profile, and with many, long yellow hairs on lower inner margins of third and fourth tergites.

Female, $4.5 \mathrm{~mm}$. long. Head as in male, but pruinescence more cinereous gray; the fulvous area of antennae reduced to base of third segment. The anterior parafrontal bristle distinctly longer than the setula just behind it.

Thoracic pruinescence more cinereous gray and the vitta narrower and more well defined postsuturally than in male.

The preapical brownish area on $\mathrm{F}$ darker and more extensive than in male. F1 with av setulae somewhat stronger, but not spinulose. T1 with mid $d$ and apical $p d$ and $p v$ shorter and stouter. F2 with 3-4 short $a v$ setulae on basal 0.5 and 4 widely separated $v$ to $p v$ bristles, a strong median $a$, and 3-4 shorter ones basad. F3 with av shorter, stouter, and less numerous than in male, but with some short, almost spinulose, interspersed setulae. T3 as in male, but the median $p d$ absent.

Abdomen not as extensively yellow dorsally, and only the basolateral angles of first and second tergites fulvous, sparsely gray pruinescent, the 
remainder of dorsum of these tergites subshiny black; third with a broad, subtriangular, median, subshiny spot, the lateral areas densely gray pruinescent; the fourth densely gray pruinescent, but with a narrow, dark longitudinal vitta.

SPECIMENS EXAMINED. - 2 males, 3 females, El Yunque, P.R., March 20-22, 1954 (J. Maldonado and S. Medina); 1 male, Luquillo Nat. Forest, P.R., "11. 18. 1925, F5113A", (Holotype).

\section{NEODEXIOPSIS DISCOLORISEXUS, NEW SPECIES}

Male, $3.3 \mathrm{~mm}$. long. Head black, with dense grayish pruinescence except on each side of the complete frontal triangle, where it is rather sparse. Front at vertex about $0.20-0.25$ of head width ${ }^{3}$; juncture of parafacials and parafrontals narrowly projecting, parafacials obscured below. Cheeks about 0.5 as high as width of third antennal segment; with dark, bristlelike setulae along lower margin. Anterior ocellar bristles shorter than postocellars and anterior parafrontals; inner and outer verticals only slightly longer than setulae in postoccular row. Antennae dark, the apex of second segment somewhat grayish fulvous; inserted opposite dorsal 0.4 of eyes and reaching to opposite their ventral margin; third segment 3.0 times as long as second. Longest aristal hairs equal to greatest aristal diameter. Palpi dark brown to fuscous.

Thorax dark, densely grayish to bluish gray pruinescent, and with 5 well defined brown vittae which are in the $a c, d c$, and $i a$ planes. Setulae in ac series biseriate, the prescutellar pair distinct and in almost the same longitudinal plane as the setulae; ia 2, subequal, well-defined. Humeral setulae normal, but more numerous than usual; setulae on anterior declivities of mesonotum normal, but with the accessory $d c$ setula on the anterior margin somewhat more spinelike than usual; with 2 stigmatal and propleural bristles; apical scutellars strong; st in an equilateral triangle.

Legs yellow, usually with a faint to well-defined dark $p d$ area on F1 and at apices of F2 and F3. F1 normal. T1 with a median $p$ bristle, the mid $d$, apical $p d$ and $p v$ subequal, about 2 times as long as T1 diameter. F2 with 2-3 $a$ and $v$ bristles on median 0.5 , and with 2 preapicals on $p$ surfaces. T2 with a submedian $a$ and $p$; the $a$ situated apicad to the $p$; the apical ad usually undeveloped, but if slightly differentiated, then shorter than T1 diameter; the apical $p d$ usually as long as $\mathrm{T}$ diameter and sometimes weakly duplicated. F3 with a complete row of av setulae which are about 0.50 as long as diameter of F3 where situated, but one near base, at middle, and apex is at least as long as $\mathrm{F}$ diameter; the $p v$ surface with irregularly long and short interspersed bristles, but those on apical $0.20-0.25$ more

all males are slightly teneral or so covered with lepidopterous scales that exact measurement is impossible. 
uniform in length and more closely placed than those on basal $0.80-0.75$. T3 with a long median, and a shorter preapical ad bristle; the mid $d$ inserted on apical $0.20-0.25$ and closer to preapical ad than to the submedian ad; without submedian $p d$ or av bristles.

Wings hyaline, often faintly tinged with brown. Costal thorns and setulae short. Calyptrae white. Halteres yellow to fulvous.

Abdomen with first 2 visible tergites predominantly yellow, the others dark in ground color. The first with a median dark area which blends into a dark triangular one on second; the dorsum of third mostly shiny black, and with a subtriangular, densely grayish pruinescent area basolaterally; the fourth mostly grayish pruinescent but with a narrow, subshiny median vitta.

Female, $4.5 \mathrm{~mm}$. long. Generally similar to the male in structural characters, but much darker in color.

Head as in male. Thorax with ac and ia vittae broad postsuturally, and almost confluent with the $d c$ vittae.

Legs mostly fuscous, the coxae, trochanters, apices of femora, and base of tibiae with limited reddish areas. F1 with av setulae on basal 0.5 stronger than in male; otherwise bristled as in male, except most of the F2 and F3 bristles and setulae stronger, and less hairlike.

Abdomen almost entirely fuscous, only the base of first visible tergite somewhat fulvous below.

TYPE MATERIAL.-Holotype, male, Kilometer 22, Yauco-Lares Road, P.R., July 18, 1953 (J. A. Ramos, J. Maldonado) at light; allotype, female, same data as type; paratypes: 7 males, 13 females, same data as type; 2 females, "Maricao S. Forest, P.R.", July 5, 1953 (J. Maldonado-Caprilles coll.); 1 female, "Maricao, P.R., Intercepted San Juan, P.R., 5-23-33, A. G. Harley, San Juan No 4243 ", and with a label in pencil, "USNM"; 2 females, El Yunque, P.R., March 20-22, 1954 (J. Maldonado and S. Medina); 1 male, Maricao Insular Forest, P.R., 30 April, 1953 (J. A. Ramos) (light trap), 1 female, Guilarte Park, Adjuntas, P.R., Feb. 13, 1954 (J. Maldonado and S. Medina); 1 female, Adjuntas, P.R., Feb. 13, 1954 (J. Maldonado and S. Medina); 1 female, "Yauco-Lares Rd., $\mathrm{Km}$. 29", Jan. 20, 1954 (J. Maldonado and S. Medina).

\section{NEODEXIOPSIS MICANS, NEW SPECIES}

Male, $2.7 \mathrm{~mm}$. long. Head dark; pruinescence on face and cheeks silvery gray; on occiput gray with a pale bluish tinge; frontal vitta brown to fuscous; frontal triangle brownish gray, extending to base of antennae as a narrow line. Front at vertex 0.27 of head width, slightly wider at middle, then narrowed to vertical width at base of antennae. Anterior and posterior ocellar bristles very short, subequal, not over 0.6 as long as the short an- 
terior parafrontals; inner and outer verticals scarcely differentiated. Median parafrontal bristles strong, slightly longer than the posterior parafrontal bristle at vertex; the reclinate parafrontals as long as the anterior pair. In profile, juncture of parafacials and parafrontals subequal to width of third antennal segment; parafacials obscured below. Cheeks as high as width of third antennal segment, the setulae on their lower margin white; vibrissae dark. Antennae yellowish fulvous, but most of the dorsal apical portion of third and base of second segments dark brown. Antennae inserted opposite middle of eyes, reaching almost to their lower margin; third segment 2.0 times as long as second. Arista bare. Palpi silvery yellow, without distinct bristles but with short, pale clothing hairs.

Thorax black, bluish to greenish gray pruinescent; with a median brown vitta of variable width and indistinct brownish lines along planes of $i a$ and $d c$ bristles. Setulae on humeri and anterior declivities of mesonotum normal but sparse; ac setulae extremely short and almost uniseriate or absent; ia 1; with a single propleural and stigmatal bristle; st in an almost equilateral triangle. Apical scutellar bristles absent, or if apparently differentiated, then shorter than the very sparse scutellar clothing setulae.

Legs shiny yellow; the tarsi become darker brown from base to apex. F1 with a row of very short but distinct $a v$ spinules on apical 0.8 ; the $p v$ bristles very slender and confined to apical 0.5 ; with the usual row of normal $p d$ bristles. T1 with 4-7 long slender $p$ hairlike bristles on apical 0.5 , which become shorter apically, the longest at least 0.75 the length of $\mathrm{T} 1$; with a distinct preapical mid $d$, but without distinct preapical $p d$ or $p v$ bristles. F2 slender, almost bare, clothing setulae confined to $d$ surfaces; with 1 short median $a$ and a single hairlike $p d$ on apical 0.25 , and with 1-2 slender $v$ hairs. T2 about 0.6 the length of F2, slightly bowed on basal 0.25 and with 4-5 long, hairlike $p$ bristles which are about 0.6 the length of T2; with a single long ad bristle on apical 0.33 ; the apical $a d$ absent; the $p d$ short but distinct. F3 long and slender; almost bare, the clothing setulae confined to $d$ surfaces; without a row of ad bristles, but with the preapical ad present; with 5-7 hairlike $p d$ on apical 0.5 and with 1-2 short, slender $a v$ and 1 long $p v$ at base. T3 0.6 as long as F3, straight; almost devoid of clothing setulae, but with a complete row of 10 or more long av bristles which are at least 0.33 the length of T3; with 2-3 slender but widely spaced $a d$ and $p d$ bristles, and a row of numerous long $p v$ on basal 0.5 ; with 4-5 long $p$ bristles along the entire length of T3; without well-defined $a$ bristles. Most of the $\mathrm{T}$ bristles are slightly curled apically.

Wings hyaline, but light brownish tinged. Costal thorns and setulae very short. Posterior cross vein straight. Calyptrae white. Halteres yellow.

Abdomen cylindrical, as long as combined length of head and thorax; glossy yellow, except a large, dark, shiny area on sides of third and dorsum 
of fourth visible tergites and with a median brown line on first and second. Clothing setulae reduced to 1-2 series on each side of the midline.

Female, $3.0 \mathrm{~mm}$. long. Head as in male except the bristles along anterior portion of ventral margin of cheeks dark and those on posterior portion white; antennae darker.

Thorax as in male, but the median brown vittae more expansive postsuturally and confluent with the vittae in $d c$ planes; and with an additional vitta in $i a$ plane.

Only the fifth tarsal segment conspicuously darker than remainder of legs. F1 as in male. T1 with a single median $p$, and with apical $p d$ and $p v$ bristles distinct. $\mathrm{F} 2$ as in male, but not quite as slender, and the clothing setulae more numerous. T2 not bowed and with a single median ad and $p d$ bristle. F3 with 2-3 $a v$ and $p v$ bristles on basal $0.50-0.66$ and with some very short interspersed setulae. T3 not bowed, with a single long, median $a d$ and without $a v$ or $p v$ bristles; the mid $d$ bristle more basally situated than usual, inserted on apical 0.4 and the preapical ad bristle more than its own length from apex of T3.

Abdomen not cylindrical; dark, the yellowish areas restricted to basolateral portions of first tergite; densely grayish pruinescent and with an indistinct median brown stripe on first 3 tergites; with a transverse brown band at apex of first; the second to fourth tergites inclusive with a pair of subtriangular apical brown spots which extend ventrally onto sides of the second and third tergites.

TYPE Material.-Holotype, male, El Yunque, P.R., March 20-22, 1954 (J. Maldonado and S. Medina); allotype, female and paratypes: 1 male and 1 female, same data as type.

The males of micans and crassicrurus lack the usual arrangment of the apical $a d$ to $p$ bristles on F3, characteristic of Neodexiopsis. Because the associated females have these bristles in the typical Neodexiopsis arrangement, these species are included in this genus, especially since the males resemble calopyga Loew and floridensis Malloch, (2) in having the sides or more of the third and fourth abdominal tergites shiny.

\section{NEODEXIOPSIS CRISPISETA, NEW SPECIES}

Male, $3.1 \mathrm{~mm}$. long. Head dark in ground color; grayish pruinescent, except the front which is densely brownish pruinescent and the parafrontals which are dark and scarcely differentiated. When viewed from above, the latter are yellowish gray pruinescent; the frontal triangle is faintly visible and reaches only midway to base of antennae. Front at vertex 0.24 of head width, amost parallel sided. In profile, parafacials and parafrontals scarcely visible. Cheeks 0.8 as high as width of third antennal segment, and with long, white, hairs on ventral portion. Anterior and posterior ocellar bristles 
very short, about as long as the hairlike setulae which are interspersed between the usual strong parafrontal bristles; inner and outer vertical bristles scarcely differentiated. Antennae dark brown, but with a narrow yellow area adjacent to base of arista; inserted opposite middle of eyes and not reaching to their lower margin; the third segment 1.8 times as long as second. Longest hairs on arista almost as long as its greatest diameter. Palpi yellowish white.

Thorax black, bluish gray pruinescent; with a brown vitta along planes of $a c, d c$, and posthumeral to $i a$ bristles; these vittae become more diffuse postsuturally and almost merge opposite the second postsutural $d c$ bristle. Setulae on humeri and anterior declivities of mesonotum normal; ac setulae sparse, almost uniseriate; ia 1. Apical scutellars 0.4 as long as subbasals. Propleural and stigmatal bristles duplicated; the lower st bristle more posteriorly situated than usual.

Legs yellow, the coxae with a whitish tinge; the tips of F2 and F3 brown and the apical 2-3 tarsal segments blend into brown. F1 with the usual row of $p d, p$ and $p v$ bristles, but ventral 0.5 of $p$ surface shiny and devoid of clothing setulae; without unusual av setulae. T1 with the median $p$, preapical $p d$ and $p v$ bristles $0.66-0.75$ as long as $\mathrm{T} 1$, almost hairlike and slightly curled apically; the mid $d$ bristle short, but somewhat more slender than usual. F2 with a complete row of slender, hairlike av bristles which are apically curved at their middle and are slightly longer than diameter of F2 where situated; with 4-5 moderately long $v$ on basal 0.33 and with 6-9 long, curly $p v$ bristles on basal 0.75 , the median ones in this series at least as long as the length of F2; and with 1 long, and 1 short $p$ preapical hairlike bristle. T2 with the $a$ and $p$ bristles more hairlike than usual and situated beyond middle; the apical $p d, p$, and $a v$ bristles very long and hairlike, somewhat crinkled, and at least 0.5 as long as length of T2; the apical $v$ bristle normal; the apical ad bristle hairlike and only 2.0-2.5 times as long as diameter of T2. F3 with the ad row of bristles long, slender, and crinkled apically; with a complete row of 9-12 av and 5-8 $p v$ hairlike bristles which are curled apically and are $0.33-0.67$ as long as length of F3; the preapical $a d, d$, and $p d$ bristles in the usual position for Neodexiopsis, but much longer and more hairlike than usual, their tips somewhat curled. T3 with an $a$ bristle slightly basad the middle, a $p d$ almost opposite it, and an ad on apical 0.33 ; another $a d$ on apical 0.2 , and a mid $d$ bristle which is inserted almost at middle of T3; all of these very long and curled or crinkled apically, and almost as long as length of T3; clothing setulae normal and without interspersed long hairs.

Wings hyaline, faintly tinged. Costal thorns and setulae not unusually modified. Posterior cross vein straight. Calyptrae white. Halteres yellow. Abdomen short, ovoid, and with large, shiny, triangular bare areas on sides of second to fourth visible tergites. The first 2 tergites yellow in 
ground color but with a median, dark brown trapezoidal spot which is thinly overlaid with gray pruinescence; this spot on first tergite smaller than the one on second, and at apex of the latter the spots extend downwardly onto the side; the third and fourth tergites light brown with dense greenish to bluish gray pruuinescence on dorsum; with 3 large, irregular, brown spots on dorsum of third, and with 2 spots on fourth tergites.

Female, $4.3 \mathrm{~mm}$. long. Head dark, grayish pruinescent; the front brownish pruinescent, and the cheeks with reddish to fulvous reflections. The frontal triangle indistinct and reaches only to middle of front, but when viewed from in front at various angles, the frontal vitta appears densely brown pruinescent and the posterior 0.5 of each parafrontal subshiny and slate gray. Front at vertex 0.20 of greatest head width, parallel sided. Cheeks 0.5-0.6 as high as width of third antennal segment; the hairs on its lower posterior portion yellowish. Anterior and posterior ocellar bristles subequal, and about 0.5 as long and strong as the rather long anterior parafrontal bristle; inner and outer vertical bristles scarcely longer than the setulae in postoccular row. Antennae fuscous, the base of third segment and apex of second narrowly fulvous; third segment 2.6 times as long as second. Palpi pale yellow, very slightly enlarged apically and with a fringe of slender, yellow, hairlike bristles along their lower margin. Otherwise head as in male.

Thorax dark, obscurely grayish pruinescent and with a trace of 3 narrow, brown vittae in $a c$ and $d c$ planes. Setulae in ac series short and sparse; the prescutellar pair scarcely differentiated. Apical scutellars $0.6-0.7$ as long as subbasals. Thorax otherwise as in male.

Legs yellow, with a purplish brown $p d$ cloud on F1, at apex of F2 and F3, and at base of mid coxae; the tarsi become more brownish from first to fifth segments. F1 with an irregular double row of very short, spinulose av setulae on basal 0.75 . T1 with a median $p$ and apical $p d$ bristle almost 0.75 the length of $\mathrm{T} 1$; with mid $d$ and apical $p v$ conspicuously shorter, the latter 1.5 times as long as $\mathrm{T} 1$ diameter. F2 with a row of slender $v$ to $p v$ bristles, the 2-3 near the median $0.50-0.66$ as long as the length of F2; with a median $a$ bristle, a few much shorter ones basad and a single one beyond; with 2-3 preapical $p$ bristles. T2 with a long, submedian $a$ and $p$ bristle; the apical ad not differentiated, but the apical $p d$ longer than $\mathrm{T}$ diameter. F3 with 3-4 widely spaced, slender $a v$ bristles, one of them on apical 0.33 longer than the others and more dorsally situated, and with a short bristle opposite the terminal one in ad series; with 3-4 pv bristles on median 0.5 , the median one longest. T3 with a long $a$ on basal 0.33 , an equally long ad slightly beyond middle and with a very short preapical $a d$ which is scarcely as long as T3 diameter; the mid $d$ as long as the $a$ and inserted at middle of $\mathrm{T} 3$ and distinctly basad to the long ad bristle.

Wings as in male. 
Abdomen apparently dark dorsally and yellow on ventral portions of sides; no marks visible, but the abdomen is greasy in the single specimen. TYPe Material.-Holotype, male, and allotype, female, El Yunque, P.R., March 20-22, 1954 (J. Maldonado and S. Medina).

\section{NEODEXIOPSIS CRASSICRURUS, NEW SPECIES}

Male, $2.8 \mathrm{~mm}$. long. Head black; when viewed from directly in front, the face with extremely dense white, and the front with silvery, pruinescence; the parafrontals differentiated only when head is viewed from above. Facial plate not concave as usual and with a narrow longitudinal median ridge which extends from base of antennae to oral margin; the latter more ventrally extended than usual, and the lower margin of head distinctly constricted posterodorsally. In profile, juncture of parafacials and parafrontals as long as width of third antennal segment, the parafacials almost obscured below their center. The distance from vibrissae to nearest point of eye as long as length of third antennal segment. Hairs on ventral portion of cheeks short, white; vibrissae dark, only as long as anterior parafrontal bristle. Front at vertex 0.33 of head width, slightly wider at middle, then narrowed to vertical width at base of antennae. Anterior and posterior ocellar bristles 0.66 as long as the relatively short anterior parafrontal bristle, and about 0.4 as long as the median parafrontals. Inner and outer vertical bristles scarcely differentiated. Antennae inserted opposite middle of eyes and terminating opposite their lower 0.2 , or about 0.66 the length of third antennal segment above oral margin. Antennae fulvous yellow, and with a darkened apical area on outer surface which extends almost to middle of third segment; first and second segments dark, but with a very narrow apical fulvous border on second; third segment 2.0 times as long as second. Arista bare. Palpi slightly enlarged apically and inwardly curved; yellowish white and with dense white pruinescence; without distinct bristles.

Thorax dark, blue to greenish gray pruinescent; with a narrow median brown vitta presuturally which becomes broader postsuturally and merges with a narrow vitta along planes of $d c$ bristles; with a mere trace of a vitta in $i a$ plane. Setulae on humeri and anterior declivities of mesonotum normal; $a c$ setulae very sparse, in a single irregular row; $i a$; apical scutellars 0.4 as long as subbasals. Lower stigmatal bristles absent; st 1:2 and not in an equilateral triangle.

Legs fulvous, mid and hind coxae somewhat fuscous basally; apices of fifth tarsal segments, claws and pulvilli black. F1 somewhat more swollen on basal 0.5 and narrower on apical 0.5 than usual; mostly shiny and bare; the clothing setulae in only 1-2 irregular $p d$ rows; the bristles in the $p d$ row very short and sparse; the $p v$ surface with an irregular double row of short, spinulose setulae on apical 0.5 and with a single row of shorter ones 
on basal 0.5 ; with a complete row of av spinules. T1 with 2 long median $p$ bristles and with several shorter ones which extend to apex, the latter setae about twice as long as T1 diameter. F2 shiny; clothing setulae confined to $a d$ and $d$ surfaces; with a single short $a$ bristle on basal $0.33-0.50$ and with very short, somewhat spinulose setulae along $a v$ and $p v$ surfaces; without any preapical bristles on $p$ surfaces. T2 very narrow basally, becoming thicker apically, so that the distal 0.25 is almost as thick as the basal 0.25 of F2; the enlarged portion of T2 with several $a d$ and $p d$ series of long, irregular hairlike setulae and bristles. F3 narrowed on apical 0.2 and somewhat more swollen on basal 0.8 than usual, shiny; clothing setulae confined to ad and $p d$ regions and without the usual row of $a d$ bristles, the $a v$ and $p v$ surfaces with only very short, spinulose setulae, and without a clearly defined apical $a v$ bristle. T3 slightly bent on basal 0.25 and with an $a d$ bristle at basal $0.25-0.33$; a row of 5-6 long, curled, bristlelike $a v$ hairs; and with a row of long, curved $p d, p$ and $p v$ bristles which are longest on the basal 0.4-0.6.

Wings hyaline. Costal thorns and setulae short. Calyptrae whitish hyaline. Halteres fulvous yellow.

Abdomen subcylindrical; when viewed dorsally, with a dark median dorsal area which becomes broader apically on first and second visible tergites; the entire dorsum of third and fourth dark, but with a narrow, median brown vitta. Sides of first and second, and ventral portion of all tergites yellowish to fulvous. When viewed laterally, with a large irregular shiny area on first and second tergites; and darker narrower ones on basal portion of third and fourth; the gray pruinescence extends progressively more ventrad on sides of second to fourth tergites respectively. Dorsum of all tergites with the usual decumbent clothing setulae.

Female, $3.2 \mathrm{~mm}$. long. Generally resembling male, but without the modified face and oral margin. Tibiae and femora not unusually modified in shape or bristling.

Front with grayish brown pruinescence; frontal triangle extends narrowly to base of antennae. In profile, parafacials and parafrontals mostly obscured, but their juncture clearly visible. Cheeks as high as width of third antennal segment. Fulvous area on the antennae limited to base of third and apex or more of second segments. Palpi slender, not apically bent; yellow.

Thorax marked and bristled as in male, except the apical scutellar bristles are scarcely differentiated; only 1 propleural bristle present.

Legs yellow, tarsi brownish. F1 with a row of short, weak spinulose $a v$ setulae on basal 0.8 , but with the usual $a v$ and $p v$ bristles; $p$ surface shiny, without clothing setulae. T1 with a long median $p$, a shorter preapical mid $d$, and apical $p d$ and $p v$ bristles, the latter two about 2 times as long 
as T1 diameter. F2 with sparse but uniformly distributed clothing setulae; a strong and a weak median $a$ bristle, a slender $v$ and a single preapical $p$ bristle. T2 with a long median $a$ and 1 long and 1 short median $p$ bristle; the apical ad absent and the pd short. F3 shiny, with 2-3 short av and $p v$ bristlelike hairs on basal 0.75 and with short, interspersed setulae; clothing setulae very sparse or absent on most of $a$ and $p$ surfaces. T3 as in female of micans.

Abdomen as in female of micans.

TYPE Material.-Holotype, male, El Yunque, P.R., March 20-22, 1954 (J. Maldonado and S. Medina); allotype, female and paratypes: 2 males, same data as type.

The presence of $2 p$ bristles on T2 in the above female specimen is very unique, and since there are several $p$ bristles on T2 of male, I am associating the allotype with the males in the type series, despite the much shorter length of the apical scutellar bristles in the female.

\section{NEODEXIOPSIS EBENIFEMUR, NEW SPECIES}

Female, 3.1-3.3 mm. long. Head black, grayish pruinescent; the front brownish tinged and the frontal triangle narrowly complete. Front at vertex 0.24 of head width, slightly wider at middle, but narrowed to vertical width at base of antennae. In profile, parafacials and parafrontals almost or completely obscured; only their juncture slightly protruding. Cheeks 0.8 as high as width of third antennal segment. Anterior and posterior ocellar bristles subequal, the anterior one $\mathbf{0 . 6}$ as long as the short anterior parafrontal bristle. Inner and outer verticals about as long as anterior ocellar bristles. The fuscous antennae inserted opposite dorsal 0.4 of eyes and ending slightly above their lower margin; third segment 2.8 times as long as second. Longest hairs on arista slightly shorter than its greatest diameter. Palpi fuscous.

Thorax fuscous, grayish brown pruinescent; with traces of brown vittae in $a c$ and $d c$ planes. Setulae on humeri and anterior declivities of mesonotum normal; ac setulae very short and sparse, but with a well-defined and widely separated prescutellar pair; $i a 1$, or if 2 , then the anterior one is scarcely differentiated from clothing setulae. Apical scutellars 0.4 as long as subbasals; with 1 long and 1 short stigmatal and propleural bristle; st $1: 2$, not in an equilateral triangle.

Legs black, the knees and basal portion of tibiae dark yellow to brown; the basal posterior surface of F3 and sometimes base of F1 and F2 shiny black, remainder of femora sparsely grayish pruinescent. F1 with a row of short and somewhat spinulose $a v$ setulae on basal $0.75-0.80$. T1 with a long median $p$ bristle; the mid $d$ situated at apical 0.25 , and is $2.5-3.0$ 
times as long as the apical $p d$ and $p v$ which are only slightly longer than $\mathrm{T} 1$ diameter. F2 with 3-4 widely separated $v, 2-3$ submedian $a$, and 2 preapical $p$ bristles. T2 with a strong median $a$ and $p$ bristle; the apical ad not differentiated, and the apical pd scarcely as long as T2 diameter. F3 with 1-2 strong $a v$ bristles at apical 0.33 , and some short setulae basad; without an apical av opposite the terminal ad bristle; and with 3 long, slender $p v$ bristles on median 0.5 . T3 with the mid $d$ bristle long and medianly situated, a long ad bristle basad to the middle, and another somewhat shorter one which is situated on apical 0.20 ; without $a v$ or $p d$ bristles.

Wings grayish hyaline. Costal thorns and setulae short. Calyptrae concolorous with wings. Halteres fulvous yellow.

Abdomen somewhat elongate; fuscous; grayish pruinescent, and with a broad, brown, subtriangular band on apical $0.50-0.75$ of first to third visible tergites; the fourth with only a median brown stripe.

TYPE Material.-Holotype, female, El Yunque, P.R., March 20-22, 1954 (J. Maldonado and S. Medina); paratypes: 1 female, same data as type; 2 females same data as type except, "J. Maldonado Capriles, coll.".

\section{NEODEXIOPSIS DITIPORTUS, NEW SPECIES}

Male, 3.00-3.25 mm. long. Head black, dull gray pruinescent; frontal vitta, except the incomplete frontal triangle, dull velvety black. Front at vertex $0.36-0.38$ of head width, gradually narrowed to $0.30-0.33$ at base of antennae; the face very slightly constricted opposite middle of third antennal segment. In profile, juncture of parafacials and parafrontals $0.75-0.90$ as long as greatest width of third antennal segment, the parafacials obscured below. Cheeks 0.5 as high as width of third antennal segment. Anterior ocellar bristles stronger than anterior parafrontals and about as long as the reclinate posterior parafrontal pair; posterior ocellar bristles $0.4-0.6$ as long as anterior ocellars; inner verticals shorter than outer pair and the latter about 2 times as long as setulae in the postoccular row. Antennae fuscous, inserted opposite dorsal 0.4 of eyes and extending to opposite their lower level, and also to oral margin; third antennal segment 4.0 times as long as second, retreating basally on the posteroventral margin, but not sharply pointed apically. Longest aristal hairs as long as, or slightly longer than, greatest aristal diameter. Palpi black.

Thorax black, dull grayish pruinescent; with a narrow median brownish to subshiny vitta, a narrower brownish one along planes of $d c$ and a broader one in the $i a$ planes but the width of vittae are quite variable. Sides of scutellum subshiny. Setulae on humeri and anterior declivities of mesonotum normal, but with a well defined accessory $d c$ setula on the declivity; ac setulae biseriate, the prescutellar pair scarcely differentiated; ia 2, 
strong, subequal; propleural and stigmatal bristles duplicated; lower st somewhat closer to posterior than to anterior st bristle. Apical scutellars strong.

Legs black, the tibiae with a variable basal portion yellow to brown, blending to fuscous apically. F1 normal, but with a few of the $a v$ setulae on basal 0.2 of ten slightly longer than other clothing setulae. T1 with a long median $p$; the preapical mid $d$, apical $p d$ and $p v$ subequal, 2-3 times as long as T1 diameter. F2 with a row of $a$ bristles on basal 0.5 , the apical one longer and stronger than others, and with a row of short, slender $v$ to $p v$ bristles on basal $0.66-0.75$. T2 with a submedian $a$ bristle and a slightly to distinctly more apically situated $p$; the apical $a d$ shorter than T2 diameter or absent; the apical $p d$ as long as, or longer than, T2 diameter. F3 with $2 a v$ bristles on apical $0.2-0.3$ and 3-4 much shorter ones on basal $0.25-0.33$, the intervening area usually bare; with 1-3 slender $p v$ bristles on median 0.5 , the median one longest when more than 1 is present. T3 with a median ad bristle, a shorter av slightly apicad to the $a d$; the preapical $a d$ about 0.5 as long as the mid $d$ which is inserted at apical 0.20-0.15.

Wings hyaline, distinctly irridescent. The decumbent costal thorns and setulae about as long as costal diameter. The clothing setulae on wing membrane somewhat more conspicuous than usual, but not distinctly enlarged. Calyptrae white. Halteres yellow.

Abdomen elongate, ovoid; dark, sparsely gray to greenish gray pruinescent. The first visible tergite mostly shiny black, the second to fourth each with an expansive, trapezoidal, subshiny, dark spot which covers most of the dorsum except a basolateral gray pruinescent area; when viewed posterolaterally a trace of a dark, median vitta overlays the expansive dark spots. In profile, the basal hypopygial segment prominent, but not globular; with a single pair of discal bristles. Superior forceps light brown to fulvous.

Female, $3.30-3.75 \mathrm{~mm}$. long. Very similar to male. Differs in having the widest part of front opposite the strong pair of median parafrontals, the front then narrowed to vertical width at base of antennae. The third antennal segment narrower, and usually not more than 3.8 times the length of second.

The tibiae, except base of fore pair, usually concolorous with femora. Femoral and tibial bristles longer and stronger.

Grayish pruinescent areas on basolateral portions of abdominal tergites somewhat more extensive than in male.

TYPe material.-Holotype, male, "Km. 22, Yauco-Lares, Rd., P.R.," July 18, 1953 (J. A. Ramos, J. Maldonado), at light; allotype, female, same data as type; paratypes: 10 males, 22 females, same data as type; 1 male "Yauco-Lares Rd., P.R., Km. 29, Jan. 20, 1954" (J. Maldonado, S. Me- 
dina); 1 female, Maricao Insular Forest, P.R., April 30, 1953, light trap, (J. A. Ramos).

This species is very similar to the widespread Nearctic and Neotropical rufitibia Stein $(5,6,7)$; but differs in having the third antennal segment of male somewhat shorter and narrower; the abdominal spots more expansive, and the base or more of tibiae usually lighter colored. Eventually it may be found that ditiportus is a member of a cline, sensu Huxley, but until populations from other Caribbean Islands are available for comparison and for mating experiments, it is considered to be distinct from rufitibia.

\section{NEODEXIOPSIS MEDINAI, NEW SPECIES}

Male, $3.0 \mathrm{~mm}$. long. Head dark, grayish pruinescent; the cheeks with somewhat fulvous reflections. Parafrontals and frontal triangle moderately distinct, the latter narrowly complete. Front at vertex 0.24 of head width, almost parallel sided. Parafacials and parafrontals scarcely visible in profile. Cheeks 0.5 as high as width of third antennal segment. Anterior and posterior ocellar bristles $0.5-0.6$ as long as the pair of short anterior parafrontal bristles; inner and outer verticals scarcely differentiated. Antennae inserted opposite middle of eyes and extending to almost opposite their lower margin; the fulvous third segment 2.3 times as long as the light-tipped, dark, second segment; arista brown, except the fulvous first segment; the longest hairs 2.0 times as long as greatest aristal diameter. Palpi yellowish brown, darker at base.

Thorax dark, grayish pruinescent; with a median brown vitta, and a postsutural one in ia planes. Setulae on humeri and anterior declivities of mesonotum normal; ac setulae sparsely biseriate presuturally, and irregularly uniseriate postsuturally, the prescutellar pair distinct; ia 2, equal; stigmatals and propleurals 2 ; apical scutellar bristles about 0.8 as long as subbasals.

Legs entirely yellow. F1 normal but with a small $p v$ area which lacks clothing setulae. T1 with the median $p$ bristle very slender, the preapical mid $d$ slightly longer and stronger than the apical $p d$ and $p v$ which are about 2.0 times as long as T1 diameter. F2 with 4-6 $v$ to $p v$ bristles which are longest just beyond middle; without $a$ bristles or any preapicals on $p$ surfaces. T2 with a median $a$ and $p$ bristle, the apical $a d$ well developed, the $p d$ not differentiated. $\mathrm{F} 3$ with a single preapical $a v$ bristle and a row of slender setulae basad to it which are $\mathbf{0 . 3 3}$ as long as F3 diameter where situated; with a long bristle on the apical 0.33 which is inserted on the lower 0.25 of the $a$ surface and therefore appears to be a second, somewhat more $d$ situated bristle in the $a v$ series; with 2-3 short $p v$ setulae on apical 0.2 which are almost as long as diameter of F3 where situated. T3 with a row of $p v$ to somewhat $v$ bristles which become longer towards apex, the 
longest about 0.5 the length of $\mathrm{T} 3$; and with numerous long, slightly curled $a, a d$ and $d$ bristles which become longer apically, the longest equal to T3 length.

Wings hyaline, very faintly tinged with brown; costal thorns and setulae short. Posterior cross-vein straight. Anal angle rounded, and posterior margin without an incision. Calyptrae whitish. Halteres pale fulvous yellow.

Abdomen short. In profile, the first 3 visible tergites greatly thickened dorsoventrally, the fourth strongly retreating anteroventrally. The first tergite entirely yellow. The second yellow on sides and at base above, but blending into gray, and with a median brown vitta and traces of a round, brown, central spot on each side. Third and fourth tergites gray on dorsum and upper 0.5 of sides, remainder yellow; with a median brown vitta and a pair of brown spots on apical portions. In dorsal view, all tergites subequal in length. Hypopygium not prominent in profile.

Female, $3.5 \mathrm{~mm}$. long. Head as in male, but third antennal segment with extensive dark areas at apex which are continued basally along dorsal surface; the posterior ocellar bristles distinctly longer and stronger than anterior pair. Apical scutellars as long as subbasals.

Tips of F2 and F3 with a very small brownish area and a faint pd cloud on F1. F1 with av setulae on basal 0.5 more spinulose than in male, and in 3 irregular rows. T1 with the bristles stronger. F2 with the median $a$ bristle somewhat more ventrally situated; and with 2 strong preapicals on $p$ surface. F3 with the $a v$ setulae longer than in male and with numerous short, interspersed, spinulose setulae; the preapical bristles more $a v$ situated than in male, but clearly differentiated from the apical $a v$; and with $2-4$ distinct $p v$ on median $0.50-0.75$. T3 without rows of long, curled bristles, but with a strong $a$ on basal 0.33 ; with a long median $a d$ and some adjacent clothing setulae slightly longer and more upright than usual; the preapical ad bristle 0.75 as long as the median one and situated at apical 0.33 , the mid $d$ long and situated slightly beyond middle of T3; without median $a v$ or $p v$ bristles.

Abdomen more pointed than in male, and not dorsoventrally thickened; dorsum mostly grayish, but sides and ventral portion of tergites mostly yellowish; with an elongate median, brown subtriangular spot on dorsum of first and fourth.

TYPE Material.-Holotype, male, El Yunque, P.R., March 20-22, 1954 (J. Maldonado and S. Medina); allotype, female and paratype: 1 female, same data as type.

\section{NEODEXIOPSIS CAVALATA, NEW SPECIES}

Male, $2.9 \mathrm{~mm}$. long. Similar to medinai, in most characters, but differs in having cheeks without fulvous reflections; third antennal segment 2.0 
times as long as the entirely fuscous second, and ending distinctly above lower margin of eyes.

Thorax with the vittae wider, the postsutural ac setulae more regularly biseriate, and the apical scutellars as strong as subbasals.

Legs as in medinai except T1 without a preapical pd bristle.

Wings with basal angle truncate as in females of ovata Stein (5), but with a long, shallow incision along the basal 0.5 of posterior margin.

Abdomen not as extensively yellow as medinai and only the dorsum of first visible tergite yellow, but with more extensive bluish gray areas on sides of second to fourth tergites.

Female, $3.75 \mathrm{~mm}$. long, very similar to the male, and also to the female of medinai; it differs from the latter in having the third antennal segment entirely fulvous yellow; ac setulae more numerous; and tips of F2 and F3 not darkened.

Posterior margin of wing with a shallower incision and the anal angle not as distinctly truncate as in male. Both sexes, therefore, differ from medinai which has no trace of a posterior incision and has the anal margin distinctly rounded in both sexes.

TYPE MATERIAL.-Holotype, male, El Yunque, P.R., March 20-22, 1954 (J. Maldonado and S. Medina); allotype, female, same data as type; paratype: 1 female, Maricao Insular Forest, P.R., April 30, 1953, light trap (J. A. Ramos).

\section{NEODEXIOPSIS NEOFLAVIPES, NEW SPECIES}

Male, $2.8 \mathrm{~mm}$. long. Head dark; face densely yellow, front yellowish gray, and occiput grayish pruinescent; cheeks yellowish anteriorly, blending into gray posteriorly. Parafrontals slightly differentiated from frontal vitta; with a faint, narrow, but complete, frontal triangle which is best seen in dorsal view. Front at vertex 0.30 of head width, parallel sided. Anterior and posterior ocellar bristles short, 0.5 as long as the anterior parafrontals; the latter distinctly shorter than the median parafrontals; inner and outer verticals short but distinct and not quite as long as postocellars. In profile, juncture of parafacials and parafrontals projecting anteriorly a distance equal to 3.0 times the greatest aristal diameter; the parafacials narrowed to greatest aristal diameter below. Cheeks 0.5 as high as width of third antennal segment. Antennae bright fulvous to orange, inserted opposite middle of eyes and terminating slightly above their lower margin; third segment 2.0 times as long as second. First aristal segment orange, others dark brown; the longest hairs equal to greatest aristal diameter. Palpi slender, fulvous and with a few short, dark apical setulae.

Thorax dark, densely grayish to greenish gray pruinescent; with a narrow brown median vitta and another much fainter one along planes of $d c$, posthumeral and $i a$ bristles. Setulae on humeri and anterior declivities of 
mesonotum normal; ac setulae sparse, irregularly biseriate; $i a 2$; apical scutellars $0.20-0.25$ as long as subbasals. Stigmatal and propleural bristles duplicated. Lower st somewhat closer to posterior than to anterior st.

Legs entirely yellow to fulvous yellow. F1 normal. T1 with the median $p$ bristle very short, almost hairlike; mid $d$ close to apex; the apical $p d$ and $p v$ hairlike, 1.5-2.0 times as long as $\mathrm{T} 1$ diameter. F2 with a complete row of 7-9 $v$ to $p v$ bristles which are pale, very slender and about as long as diamter of $\mathrm{F} 2$ where situated; without any $a$ bristles; and with 2 preapical $p$ bristles. T2 with the median $a$ and $p$ bristles very short, scarcely longer than T2 diameter; the apical $a d$ and $p d$ only slightly differentiated from clothing setulae. F3 with a complete row of short, fine av setulae which are not quite so long as diameter of F3 where situated, the apical one stronger and darker than others and situated opposite the terminal bristle in ad row; $p v$ surface with a few of the clothing setulae at base slightly longer than usual. T3 with the median and preapical ad bristle about as long as T3 diameter; the mid $d$ longer and situated on apical 0.33 .

Wings hyaline, costal thorn and setulae short. Calyptrae whitish hyaline. Halteres yellow.

Abdomen short, somewhat ovoid and dorsoventrally.thickened; yellow but with an extensive shiny dark area on sides of third and fourth tergites. Dorsum of fourth darkened, grayish pruinescent and with a pair of round, dark spots; third with a pair of smaller preapical spots.

Female, 3.0-3.2 mm. long. Similar to male; front and face more grayish pruinescent and the parafrontals and the frontal triangle very distinct. Postocellar and vertical bristles stronger.

Thoracic vittae broader.

Legs as in male, except all tibial bristles longer and stronger. F2 with a strong median $a$ bristle; a series of short, more ad situated ones on basal 0.40 which terminate in a slightly longer bristle. F3 with 4-5 widely spaced $a v$ bristles, and numerous short, intervening setulae; with 3-4 pv bristles on basal 0.5 .

Abdomen more pointed than in male; yellow, and without shiny spots. Each tergite except fourth with a grayish brown apical band on dorsum which becomes more extensive from first to third tergites, so that it covers most of third, and extends ventrally onto sides of all tergites. Second and third tergites with a median stripe; third with indistinct paired brown spots as in male. Fourth tergite yellow apically, brownish gray basally but with paired brown spots as in male.

TYPE Material.-Holotype, male, El Yunque, P.R., March 20-22, 1954 (J. Maldonado and S. Medina); allotype, female, same data as type; paratypes: 3 females, same data as type; 1 male, Henry Barraks, P.R., 
June 19, 1952 (F. S. Blanton); 1 female, Peñón del Collao, Salinas, P.R., at light, (J. A. Ramos and J. Maldonado).

\section{NEODEXIOPSIS MALDONADOI, NEW SPECIES}

Female, $3.0 \mathrm{~mm}$. long. Head dark, grayish pruinescent but with slight yellowish reflections on face. Front at vertex 0.31 of head width, almost parallel sided; the face very slightly constricted at middle. The almost square frontal vitta with very indistinct brownish reflections, and when viewed anteriorly without a well-defined frontal triangle. Anterior ocellar bristles slightly longer than anterior parafrontals, and subequal to the predorsal, reclinate parafrontal bristles, the latter distinctly shorter than the strong, upright, posterior pair. Posterior ocellar bristles $0.75-0.50$ as long as inner and outer vertical bristles respectively. In profile, juncture of parafacials and parafrontals scarcely protruding; the parafacials obscured below. Cheeks almost as high as width of third antennal segment. Antennae dark, but with limited, pale reflections at apex of second segment; the third 2.0 times as long as second. Antennae inserted opposite middle of eyes and reaching to opposite their lower margin. Longest hairs on arista 2.0 times as long as its greatest diameter or 0.25 as long as width of third antennal segment. Palpi black at apex, blending into brown at base.

Thorax cinereous; grayish pruinescent; with a narrow median vitta, another in planes of $d c$ bristles and a very faint one in the ia planes. Setulae on humeri and anterior declivities of mesonotum normal, but with a differentiated anterior accessory $d c$ setula; $a c$ setulae regularly biseriate on preand postsutural portion; ia 2, subequal. Apical scutellars 0.4 as long as subbasals. Lower stigmatal bristle short, ventrally curved; propleurals 2. Lower st closer to the upper one than usual and the st, therefore, not in an equilateral triangle.

Legs fuscous, except the fulvous: Tibiae, a variable but much reduced apical region on $\mathrm{F} 1$, and all metatarsi. F1 with short av setulae on basal 0.5 . T1 with a median $p$, well developed preapical mid $d$ and a shorter but well defined, $p d$ and $p v$ bristle; the latter bristles distinctly longer than diameter of T1 where situated. F2 with $3-5 a$ bristles on basal 0.5 which become longer and somewhat more ventrally situated towards middle; only a few very short $v$ to $p v$ setulae; and 2 preapical $p$ bristles. T2 with the median $a$ and $p$ bristles on same transverse plane, but the $a$ bristle slightly longer than the $p$; the apical ad well developed and longer than $p d$, but shorter than other apicals, and all longer than T2 diameter. F3 with short, irregular $a v$ bristlelike setulae, but with an $a v$ bristle opposite the terminal one in $a d$ row; with a short median $p v$ bristle. T3 with an $a$, 
$a d$, and $p d$ bristle on almost the same transverse plane on basal 0.33 ; the mid $d$ on apical 0.20 ; the preapical ad inserted closer to the mid $d$ than to apex; and with a preapical $p d$ bristle inserted midway between the mid $d$ and apex of T3; without median or submedian av bristles.

Wings pale brownish hyaline. Costal thorns and setulae slightly differentiated, but not longer than diameter of costa where situated. Calyptrae white, the lower one 2.0 times as long as upper. Halteres yellow.

Abdomen dark, grayish pruinescent; with a median brown vitta on all tergites; a pair of well-defined spots on second and third, and a much smaller pair on first tergite.

TYPe Material.-Holotype, female, El Yunque, P.R., March 20-22, 1954 (J. Maldonado and S. Medina).

There is a superficial resemblance of maldonado $i$ to the Holarctic Coenosia humilis Meigen, (2) in general color and in the presence of an $a$ bristle on T3. However, the arrangment of the apical F3 bristles characteristic of Coenosia sensu stricto, the narrower front, and absence of a $p d$ bristle on basal 0.33 of T3 will readily separate humilis from maldonadoi.

\section{SUMMARY4}

Only one species of Neodexiopsis was known from Puerto Rico. The genus belongs to the Family Muscidae of the Diptera. The author describes 10 new species in the genus, namely: Discolorisexus, micans, crispiseta, crassicrurus, ebenifemur, ditiportus, medinai, cavalata, neoflavipes, and maldonadoi. A key for the identification of the species is included. This peculiar group of flies is limited to the higher altitudes of the Island, the species having been collected from the following localities: El Yunque Mts., Maricao Commonwealth Forest, and the mountainous Lares-Yauco area.

\section{RESUMEN4}

Solamente una especie de mosca del género Neodexiopsis ha sido informada de Puerto Rico. El género pertenece a la Familia Muscidae de la Orden de los Dipteros. El autor describe 10 nuevas especies, a saber: Discolorisexus, micans, crispiseta, crassicrurus, ebenifemur, ditiportus, medinai, cavalata, neoflavipes y maldonadoi. Se incluye en este trabajo una clave taxonómica para la identificación de las especies. Este interesante grupo de moscas vive en las alturas de la Isla y varias especies fueron recolectadas en las siguientes localidades: Las montañas de El Yunque, el Bosque Estatal de Maricao, y el área montañosa comprendida entre Lares y Yauco.

${ }^{4}$ Summary and Resumen prepared in Puerto Rico by Dr. L. F. Martorell of the Department of Entomology, Agricultural Experiment Station, University of Puerto Rico, Río Piedras, P.R. 


\section{LITERATURE CITED}

1. Huckett, H. C., A Systematic Study of the Anthomyiinae of New York, with Especial Reference to the Male and Female Genitalia, Memoir 77, Cornell Univ. Agr. Exp. Sta., pp. 1-91, 1924.

2. - A Revision of the North American Species Belonging to the Genus Coenosia Meigen and Related Genera (Diptera, Muscidae), pt. I, Trans. Amer. Ent. Soc., 60 57-118, 1934.

3. van Emden, F. I. Calyptrata (1), Section (a), Tachinidae and Calliphoridae, Handbooks for the Identification of British Insects, 10, Diptera: Cyclorrhapha, Royal Ent. Soc. London, pp. 1-133, 1954.

4. Malloch, J. R. Muscidae: Diptera of Patagonia and South Chile, pt. VII, Fascicle 2, British Museum (Natural History), pp. 171-346, 1934.

5. Stein, P. Nordamerikanische Anthomyiden, Beitrag zur Dipterenfauna der Vereinigten Staaten, Berl. ent. Ztschr., 42 (1897), 161-288, 1897.

6. - Die Anthomyidengattungen der Welt, analytisch bearbeitet, nebst einem kritisch-systematischen Verzeichnis aller aussereuropaischen Arten, $\mathrm{Arch}$. $\mathrm{Na}$ turgesch., 83 (1917), 85-178, 1919.

7. - Nordamerikanische Anthomyiden, 2 Beitrag, Arch. Naturgesch., 84 (1918), 1-106, 1920. 